\title{
BMJ Open Intimate partner violence among reproductive-age women with chronic mental illness attending a psychiatry outpatient department: cross-sectional facility-based study, Addis Ababa, Ethiopia
}

Tigist Zerihun (D) , ${ }^{1}$ Markos Tesfaye, ${ }^{1}$ Negussie Deyessa, ${ }^{2}$ Delayehu Bekele ${ }^{3}$

To cite: Zerihun T, Tesfaye M, Deyessa N, et al. Intimate partner violence among reproductive-age women with chronic mental illness attending a psychiatry outpatient department: cross-sectional facility-based study, Addis Ababa, Ethiopia. BMJ Open 2021;11:e045251. doi:10.1136/ bmjopen-2020-045251

- Prepublication history for this paper is available online To view these files, please visit the journal online (http://dx.doi. org/10.1136/bmjopen-2020045251).

Received 25 September 2020 Accepted 01 October 2021

A) Check for updates

(c) Author(s) (or their employer(s)) 2021. Re-use permitted under CC BY-NC. No commercial re-use. See rights and permissions. Published by BMJ.

${ }^{1}$ Department of Psychiatry, St Paul's Hospital Millennium Medical College, Addis Ababa, Ethiopia

${ }^{2}$ School of public health, Addis Ababa University, Addis Ababa, Ethiopia

${ }^{3}$ Department of obstetrics and gynecology, St Paul's Hospital Millennium Medical College, Addis Ababa, Ethiopia

Correspondence to Dr Tigist Zerihun; zerukaye@gmail.com

\section{ABSTRACT}

Objective To determine the prevalence of intimate partner violence (IPV), and associated factors, in reproductive-aged women attending psychiatric outpatient departments.

Design Cross-sectional facility-based study.

Setting Outpatient psychiatric clinics of public hospitals in Addis Ababa.

Participants Reproductive aged women with chronic mental illness (CMI) who attended follow-up in psychiatric outpatient clinics.

Primary and secondary outcome measures The data were collected using a multi-culturally validated instrument from randomly sampled women with $\mathrm{CMI}$. Multiple logistic regression was used to identify factors independently associated with IPV.

Result Four hundred and twenty-two women who were attending the psychiatric outpatient clinics took part in the study. The majority of participants $62.0 \%$ (95\% Cl 56.1 to 68.8) experienced IPV at least once in their lifetime. The most common form of IPV experienced by women was emotional violence $(60 \% ; 95 \% \mathrm{Cl} 55.0$ to 64.7$)$. One hundred and eighty-six (44.1\%; $(95 \% \mathrm{Cl} 39.3$ to 48.8$))$ respondents experienced physical or sexual violence during the last year. A history of divorce (Adjusted Odds Ratio $[\mathrm{AOR}]=5.64 ; 95 \% \mathrm{Cl} 2.75$ to 11.56 ) and having a mental illness for more than 5 years $(\mathrm{AOR}=2.23 ; 95 \% \mathrm{Cl}$ 1.26 to 3.93) were associated with any form of IPV. Conclusion The high prevalence of IPV among women attending psychiatric outpatient services highlights the need to routinely inquire about IPV and develop effective strategies to prevent it among this vulnerable group.

\section{INTRODUCTION}

Intimate partner violence (IPV) among women is a common phenomenon globally. ${ }^{1}$ According to the WHO definition, IPV includes emotional abuse, physical, sexual violence or controlling behaviour between current and ex-partners. ${ }^{2} \mathrm{Up}$ to this time, research on IPV has largely focused on experiences of physical violence than the emotional
Strengths and limitations of this study

- There is scarce research on intimate partner violence among women with chronic mental illness in Ethiopia specifically, and Africa more generally.

- We used a standard questionnaire validated for multiple countries, which allows direct comparison of our findings with other available data.

- As a cross-sectional study, our data do not imply causality and cannot inform as to the temporal relationships between the variables.

- Data were self-reported, which may be limited by recall bias and under-reporting; men were not investigated to understand the magnitude and reason for engaging in violence against their partners. The study was conducted among women thought to have better access to information, so the findings may not be generalisable to women with mental illness who do not attend psychiatric tertiary care facilities.

and sexual aspects. ${ }^{3}$ Nevertheless, one-third of women globally report having experienced IPV at some point in their lifetime. ${ }^{4}$

Studies reported considerable contextual variation in the prevalence of IPV. ${ }^{5}$ In the WHO's multi-site study, the prevalence of intimate violence in women ranged from $15 \%$ to $72.7 \%$ and $4 \%$ to $54 \%$ in their lifetime and the past year, respectively. ${ }^{6}$ In the same study, Japan (15\%) and Ethiopia (72.7\%) are countries that reported the lowest and highest physical or sexual violence against women reported, respectively. ${ }^{6}$ Another Ethiopian study has also reported a $30 \%$ prevalence among ever-married women. ${ }^{7}$ Different factors may play a role in precipitating and maintaining IPV worldwide such as marital 
status, education, wealth, cultural factors and mental health status. ${ }^{7-10}$

The link between IPV and poor mental and physical health of women have been indicated in many studies. ${ }^{11}$ IPV is associated with substantial morbidity and mortality, specifically among women, and its prevention has a major global public health importance. ${ }^{1213}$ Women who experienced IPV have more medical, gynaecological and stressrelated symptoms than those who did not. ${ }^{1214}$

There is also robust evidence that women with chronic mental illness (CMI) experience higher rates of violence than women without CMI. ${ }^{14}$ Also, IPV is an established risk factor for mental health problems, including major depression, suicide attempts and post-traumatic stress disorder. ${ }^{15-17}$ In addition to being at higher risk of experiencing different types of IPV (physical emotional and sexual), CMI's-such as severe major depressive disorder, bipolar disorder and schizophrenia hinder women's capacity to protect themselves and seek help when compared with women without CMI. ${ }^{13}{ }^{17}$ Furthermore, a history of experience of IPV is associated with poorer health, including depression, PTSD, anxiety and significant impairment in functionality and somatic health. ${ }^{11} 1517$ A study from Ethiopia found that IPV, including spousal controlling behaviour associated with depression. ${ }^{18}$ Similarly, studies from Europe, the USA and China also reported an association between mental illness and IPV. ${ }^{19}{ }^{20}$ Nevertheless, evidence is scarce about the prevalence of IPV among reproductive-age women with CMI living in resource-poor settings.

Data on IPV prevalence and its associated factors among women with CMI is essential for developing effective interventions in this targeted vulnerable group. Therefore, we aimed to investigate the prevalence of IPV and associated factors among women with CMI in Ethiopia.

\section{METHODS}

\section{Study setting and design}

Institutional-based cross-sectional study design was undertaken in public hospitals in Addis Ababa, Ethiopia. The city has an estimated population of 3.2 million. ${ }^{21}$

The study was conducted between December 2016 and May 2017 in four outpatient clinics at public tertiary hospitals that deliver specialised mental health services by psychiatrists or psychiatric residents.

\section{Determination of sample size}

The sample size was determined using the following assumptions: the prevalence of IPV among women with CMI (schizophrenia, bipolar disorder and severe major depression) $(\mathrm{p}=50 \%)$ at $95 \%$ confidence level, $\mathrm{Z}=1.96=$ the level of precision (0.05), and adding for non-response of $10 \%$; this gave a required sample size of $n=423$.

\section{Sampling procedure}

The study subjects were recruited from psychiatric outpatient clinics of the four hospitals. All women aged 18-49 years who provided consent and presented in the study period were included. To recruit the study subjects, 497 women patients were invited to participate, of which $47(9.5 \%)$ patients were excluded due to their age was below 18 years or were never in a marital relationship, $16(3.2 \%)$ were excluded due to their presentation with acute psychosis, the remaining $9(1.8 \%)$ patients were due to other exclusion criteria, and only 1 patient was excluded due to a self-withdrawal to participate. Finally, the study included 422 study participants (figure 1).

\section{Data collection and instrument}

An interviewer-administered structured questionnaire was used to collect the data. The standardised pretested Amharic version (Amharic is the national language of Ethiopia) of a multi-culturally validated IPV tool from the WHO was employed to gather information on IPV, such as sexual, physical and emotional abuse. ${ }^{6}$

Sociodemographic characteristics and disease-related characteristics of the participants were also assessed. Women who had experienced IPV were further asked to qualify for the type of experience and the timing, that is, whether it was in the previous 12 months or not. Additionally, the questions on spousal control over the respondent were adopted and used to measure and categorise with different list of items in which a woman can act without the consent of her husband/partner, including her healthcare-related activities.

The final Amharic version of the questionnaire was administrated by trained, experienced female psychiatric nurses who aimed to be respectful, non-judgmental and enable the women to feel at ease. An exit interview was conducted after each participant's follow-up visit was complete. All participants were fluent Amharic speakers.

To ensure the quality of the data, a structured questionnaire was pretested among $5 \%$ of study participants across different psychiatric outpatient clinics. Detailed discussion was held with the researchers, supervisors and data collectors after the pretest and necessary amendments were done. The supervisors and data collectors were trained over the course of 3 days. Supervisors checked the collected data on the same day for completeness and consistency.

\section{Analysis}

In order to analyse the data, Epi Data V.3.1 was used for entry and cleaning, followed by exporting to SPSS V.20.

The sociodemographic characteristics and experiences of IPV were summarised using descriptive statistics. The outcome variable was any IPV as the categorical variable of 'yes' or 'no'. Predictor variables: marital status (single, married, divorced, widowed), educational level (above high school, high school, elementary school, illiterate or no education), occupation (unemployed, housewives/ student, daily labourer/housemaid, formal employment).

To investigate the associations between participants' characteristics and IPV, we used bivariate analyses. We used a $p<0.05$ significance level for multiple logistic 


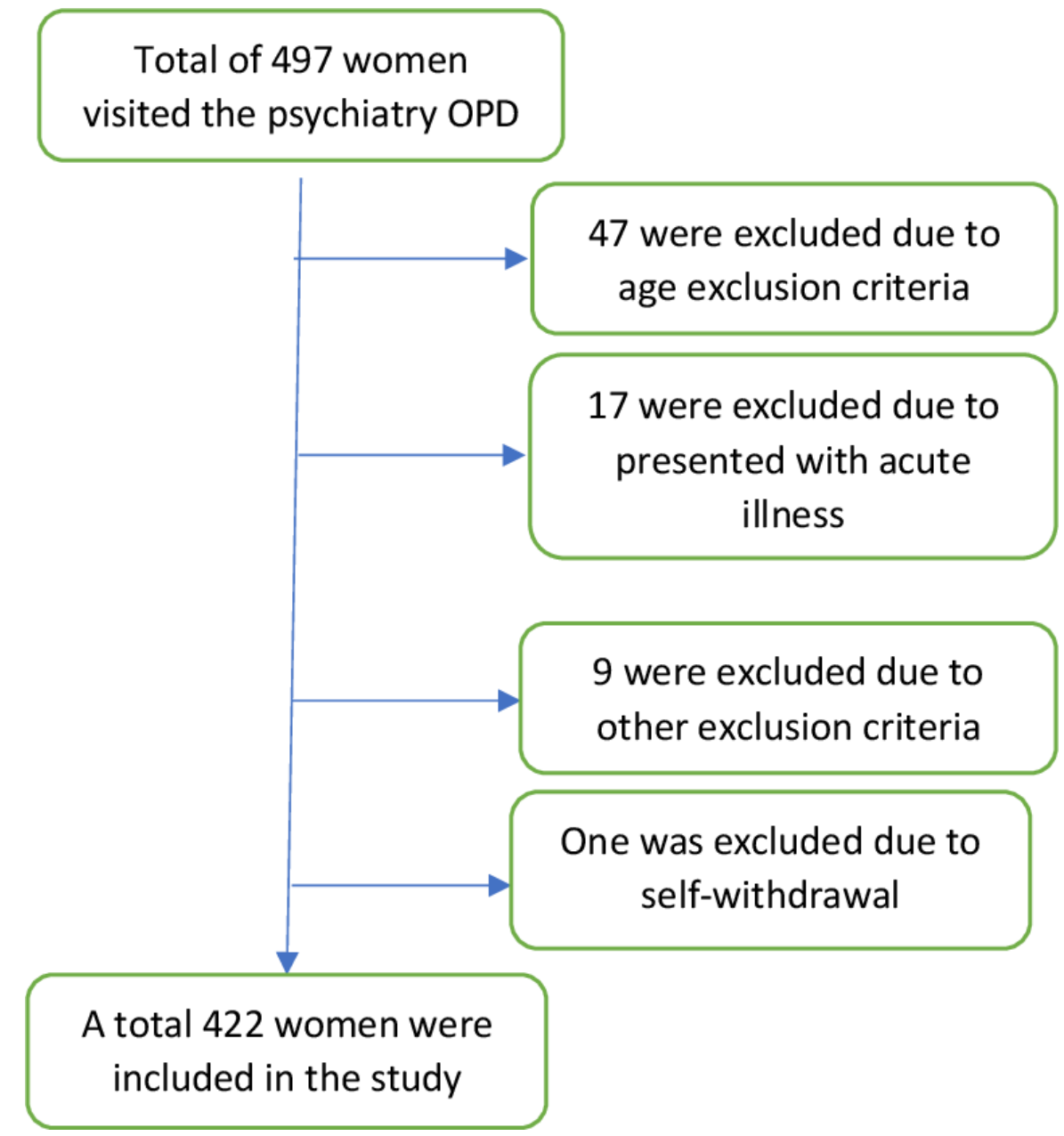

Figure 1 Sampling schedule of the selection of women included in the study. OPD, outpatient departments.

regression analysis following bivariate analysis, which calculated crude ORs and CIs 0.05 .

\section{Ethical considerations}

An experienced psychiatric nurse completed a structured assessment of the person's capacity to consent to participate in the study. Participants were informed about their right to participate only on a voluntary basis and to withdraw from the study without providing any explanation. All collected information was anonymised, and the privacy of the participants was respected in the data collection process analysis, interpretation and write up. Participants who needed any psychological or safety support during the data collection were referred for treatment and safety support. No reimbursement or payment was made for participants.

\section{Public and patient involvement}

Neither the public nor patients were involved in the study survey design. The findings will be provided for participants based on their requests. The community will be consulted as part of the design and implementation of any studies that can be built on this initial study.

\section{RESULTS}

Sociodemographic characteristics of respondents

Four hundred and twenty-three reproductive age women were approached and participated, resulting in an $99.8 \%$ response rate. The mean age of respondents was $32.1 \pm 6.7$ years, with a range of $18-46$. A third $(32.9 \%$; $n=139)$ of the participants were not married legally. Approximately 4 out of 10 women are illiterate (have no formal education) or have only a primary school education. Only $27 \%$ of women were employed (table 1). The majority $(80 \%)$ of the participants had a diagnosis of mental illness for more than 1 year. A significant proportion of the participants, $46.3 \%, \mathrm{n}=156$, lived with the illness for more than 5 years.

\section{Lifetime prevalence}

In this study, IPV was found to be prevalent in $62.0 \%$ (95\% CI 56.1 to 68.8 ) of women in their lifetimes. The most common form of IPV experienced by women was emotional abuse $(60 \% ; 95 \%$ CI 55.0 to 64.7$)$ while $38.6 \%$ (95\% CI 34.1 to 43.6$)$ of participants experienced some kind of physical violence in their lifetime. Among participants who reported physical violence, a significant proportion, $25.6 \%$ (95\% CI 21.6 to 29.6), reported severe forms 
Table 1 Participant characteristics by demographics and clinical characteristics $(n=422)$

\begin{tabular}{|c|c|c|}
\hline Characteristics & Frequency & Percentage \\
\hline$\leq 24$ & 63 & 14.9 \\
\hline $25-34$ & 186 & 44.1 \\
\hline$>35$ & 173 & 41.0 \\
\hline \multicolumn{3}{|l|}{ Marital status } \\
\hline Single & 139 & 32.9 \\
\hline Married & 187 & 44.3 \\
\hline Widowed & 26 & 6.2 \\
\hline Divorced & 70 & 16.6 \\
\hline \multicolumn{3}{|l|}{ Number of alive children } \\
\hline$>2$ & 180 & 42.7 \\
\hline $1-2$ & 84 & 19.9 \\
\hline No children & 158 & 37.4 \\
\hline \multicolumn{3}{|l|}{ Education } \\
\hline Tertiary level & 60 & 14.2 \\
\hline Secondary level (high school) & 195 & 46.2 \\
\hline Primary level & 123 & 29.2 \\
\hline Illiterate & 44 & 10.4 \\
\hline \multicolumn{3}{|l|}{ Diagnosis } \\
\hline Schizophrenia & 170 & 40.3 \\
\hline Bipolar disorder & 116 & 27.5 \\
\hline Major depressive disorder & 136 & 32.2 \\
\hline \multicolumn{3}{|l|}{ Psychotropic medication } \\
\hline Antipsychotics & 208 & 49.3 \\
\hline Mood stabiliser & 67 & 15.9 \\
\hline Antidepressant & 147 & 34.8 \\
\hline \multicolumn{3}{|l|}{ Duration of treatment in months } \\
\hline $1-24$ & 163 & 38.6 \\
\hline $25-48$ & 91 & 21.6 \\
\hline 49 months and above & 168 & 39.8 \\
\hline \multicolumn{3}{|l|}{ Occupation } \\
\hline No job & 160 & 37.9 \\
\hline Housewives/students & 93 & 22.1 \\
\hline Housemaid/daily labourer & 55 & 13.0 \\
\hline Employed (formal) & 114 & 27.0 \\
\hline
\end{tabular}

of physical violence. The common form of severe physical violence was being beaten by fist on the face $21.8 \%$ (95\% CI 17.3 to 25.6 ) followed by $13 \%$ (95\% CI 9.7 to 16.1) getting kicked in different parts of the body. Three per cent or more of the women who experienced physical violence foresaw incontinence, bleeds, fractures, or loss of consciousness. Only $2 \%$ of participants sought medical service for the incident. Moreover, 38\% (95\% CI 28.7 to 47.2) of women who experienced severe physical violence reported that the incident occurred while pregnant.

Regarding sexual violence, nearly one-third 31.3\% (95\% CI 26.8 to 36.0 ) of the study participants reported ever experiencing any form of sexual violence, and $25.1 \%$ (95\% CI 20.9 to 29.1 ) reported that their partner had compelled them to have sex.

More than one-third of all respondents, $36.2 \%$; (95\% CI 31.3 to 41.0$)$, had at least one pregnancy after they received the diagnosis of mental illness. Of these, $58.1 \%$; (95\% CI 53.1 to 62.3 ) pregnancies were unintended, and $53.9 \%(45.3,63.3)$ of which ended up in induced abortion. In 29\% (95\% CI 21.1 to 35.9) of these pregnancies arising from forced sexual intercourse, the women resorted to induced abortion and terminated the pregnancy. Additionally, a third of participants had sexual intercourse before 18 years of age, putting them at an increased risk of teenage pregnancy.

\section{Twelve months of prevalence}

Among women who participated in this survey, $44.1 \%$ (95\% CI 39.3 to 48.8 ), $35.3 \%$ (95\% CI 31.0 to 40.3 ) and $25.1 \%$ (95\% CI 21.3 to 29.9 ) reported to have experienced sexual and physical violence within the last 1 year preceding the interview, respectively. Of those who reported physical violence, 95\% (95\% CI 91.3,98.0) of them said this was severe, that is, being hit with a fist or object on the face. Two per cent of them were able to get treatment, and the other $2 \%$ spent a night in the hospital for the damage due to the physical attack by their male partner. A significant statical difference was not observed in the prevalence of IPV among women by the psychiatric diagnosis.

\section{Emotional violence and spousal control}

Almost $60 \%$ of participants had experienced moderate $25.0 \%$ (95\% CI 21.2 to 29.3 ) or severe $34.8 \%$ (95\% CI 30.0 to 39.0) forms of emotional violence, and higher than $92 \%$ (95\% CI 90.0 to 95.3) were either limited in what they could do or required permission in order to do it by their spouses in their lifetime. More than 70\% (95\% CI 67.1 to 95.3 ) of participants would not visit healthcare facilities for treatment without getting approval from their partner (table 2).

\section{Factors associated with IPV}

The logistic regression model showed marital status, occupation, duration of illness and spousal control were significantly associated with IPV (table 3 ). There was a significantly higher prevalence of physical and/or sexual violence among women without jobs (AOR $=2.35 ; 95 \%$ CI 1.23 to 4.41$)$, daily labourers or housemaids (AOR=3.33; 95\% CI 1.45 to 7.61) compared with employed women. Moreover, the OR of IPV was higher among divorced women $(\mathrm{AOR}=4.97 ; 95 \% \mathrm{CI}$ 2.36 to 10.45$)$ and non-married women (AOR $=3.56 ; 95 \% \mathrm{CI}$ to $2.09,6.04)$ compared with currently married women. The study also depicted those women diagnosed with mental illness more than 5years ago were more likely to experience IPV than newly diagnosed (AOR=2.11; 95\% CI 1.17 to 3.82). However, the study did not find a difference in IPV experienced by the level of income or educational status (table 3). 
Table 2 Spousal control among participants

\begin{tabular}{|c|c|c|}
\hline Types of spousal control & Never $\mathbf{N}(\%)$ & Yes $\mathbf{N}(\%)$ \\
\hline Have you ever been prohibited not to meet your friend by your partner? & $210(49.8)$ & $212(50.2)$ \\
\hline Does your partner make a restrict/limit limitation on your contact with your family? & $234(55.5)$ & $188(44.5)$ \\
\hline $\begin{array}{l}\text { Does your partner make sure you always know where you are; always want to know where } \\
\text { you are? }\end{array}$ & $189(44.8)$ & $233(55.2)$ \\
\hline Does your partner ignore or treats you indifferently? & $153(36.3)$ & $269(63.7)$ \\
\hline Does your partner become annoyed when you talk with other men? & $113(26.8)$ & $309(73.2)$ \\
\hline Does your partner often accuse you of being unfaithful? & $148(35.1)$ & $274(64.9)$ \\
\hline Does your partner want to ask him permission when you go out from home? & $117(27.9)$ & $303(72.1)$ \\
\hline Does your partner want you to ask him permission before visiting the healthcare service? & $121(28.7)$ & $300(71.3)$ \\
\hline Does your partner force you not to express your feeling to other people? & $192(45.5)$ & $230(54.5)$ \\
\hline
\end{tabular}

\section{DISCUSSION}

Despite high prevalence reports of IPV in communitybased studies in Ethiopia, no study focused on women with CMI. In this study, we found a high lifetime prevalence and recent IPV in this vulnerable group of the population.
A significant proportion (62\%) of women conveyed experiences of IPV in their lifetime, which occurred quite frequently, signifying that this is a common experience of women with CMI. This finding is similar to a previous study from rural Ethiopia, which reported $60.7 \%$ violence against people with CMI. ${ }^{22}$ Likewise, the finding of IPV

Table 3 Intimate partner violence and associated factors among study participants

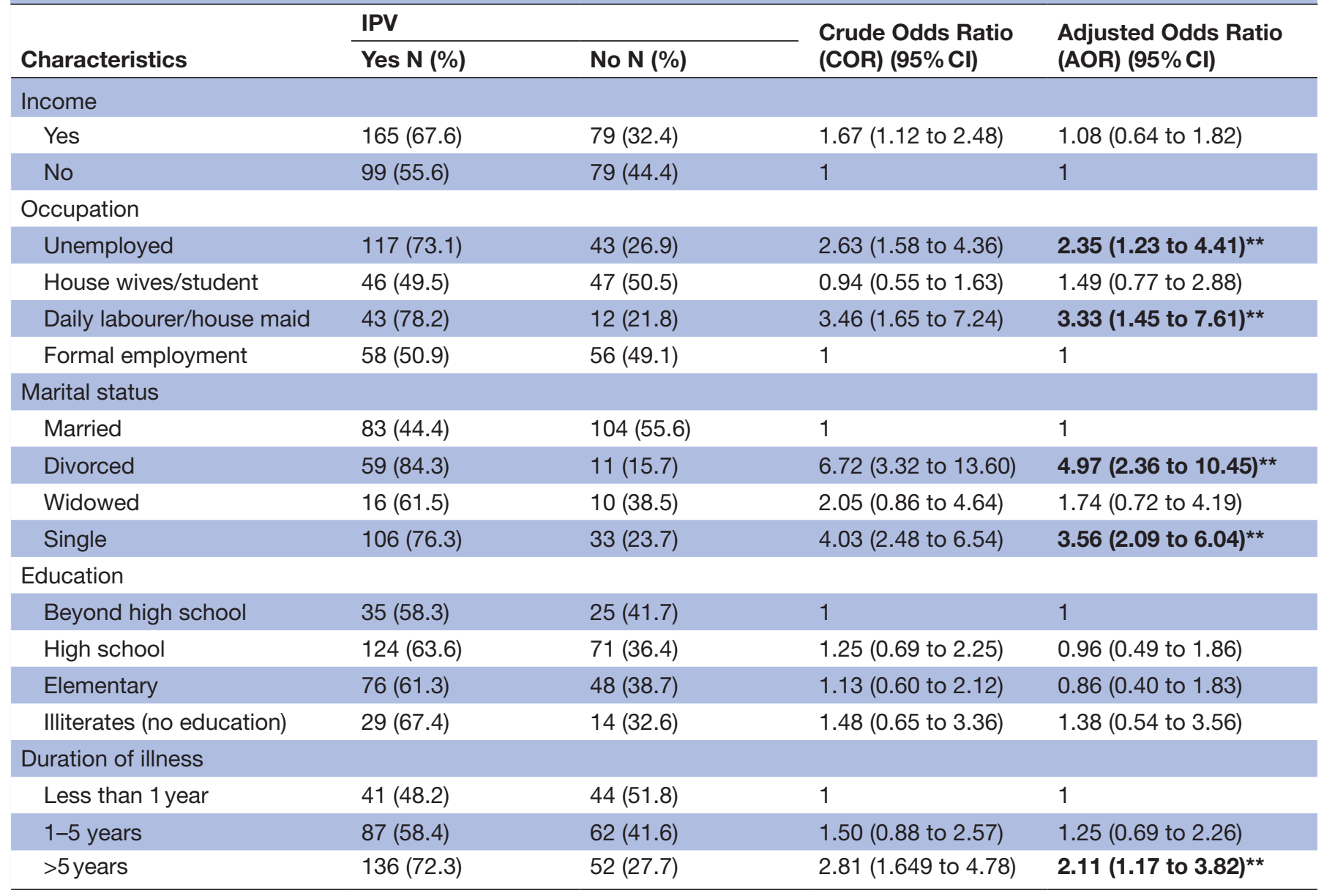

** The association is significant at $95 \% \mathrm{Cl}$ and $\mathrm{P}$ value less than 0.05

IPV, intimate partner violence. 
in this study is as high as a WHO community prevalence study report from Ethiopia, which is $72 \%,{ }^{18}$ and Tanzanian study $(61 \%) .{ }^{23}$ Our findings are also higher than a community study in northern Ethiopia ${ }^{24}$ and a report from a systematic review suggesting a prevalence of $33 \%$ IPV among women with CMI attending outpatient clinic. ${ }^{25}$ The difference can be explained by study population differences; the participants of the northern Ethiopian study were women in a rural community, while our study participants were urban residents and had higher educational levels. This study also reported (44\%) recent IPV, which is higher than studies from high-income countries, such as $21 \%$ reporting IPV in the last 12 months from the $\mathrm{UK}^{26}$ and $30.3 \%$ in Spain. ${ }^{27}$ This is consistent with the assertion that women with CMI constitute a vulnerable segment of the population who need special protection. ${ }^{9}$ Healthcare providers should investigate about all types of recent IPV among reproductive age women with CMI.

The prevalence of physical violence was also found to be high in this study (38.5\%), and this is comparable with other results from some African ${ }^{28}$ and South Asian countries. ${ }^{29}$ However, our finding is lower than the prevalence reported from rural Ethiopia, ${ }^{18}$ which may be due to under-reporting by our study participants who might be more dependent on their partners for support towards the care of their mental illness. Physical violence is an important psychosocial issue with detrimental effects on the course of the pre-existing mental illness hence contributing to gender disparities in the treatment outcomes of CMI. Additionally, our study found that IPV is associated with a longer duration of illness. Similarly, another Ethiopian study found association between IPV and depression. ${ }^{18}$

Despite a significant number of participants who reported physical violence in this study, only a small proportion sought healthcare for their injuries. This is consistent with the low level of help-seeking behaviour for IPV-related injuries as reported by other studies in Ethiopia and other global studies. ${ }^{53031}$ A varying degree of emotional violence was also reported in $60 \%$ of participants, consistent with findings from Tanzania. ${ }^{23}$ It also has a significant association with poor mental health, as reported by other African countries. 233233

This study found that violence and spousal control are common concerns in relation to the human rights and well-being of women with CMI. We found that violence in the form of physical violence was associated with violence in other forms; this is consistent with research that has found that physical violence is frequently related to sexual or and psychological coercion. Mental healthcare providers need to routinely inquire about IPV during outpatient visits to offer appropriate interventions. Our study had not found an association between IPV and women's education, which contrasts with a previous study from Sudan. ${ }^{28}$

Despite the limitations of this research, which included being a hospital-based study, purely urban sample and cultural bias of reporting, we have attempted to minimise non-disclosure in our methods. Such non-disclosure may link in with cultural taboos in relation to the topic. However, we used experienced, female psychiatric nurses do the interviews in order to prevent any discomfort to participants, and to try to minimise risk of non-disclosure. We believe that the current study's findings will help other researchers further investigate the observed relationships of IPV and CMI through longitudinal studies with larger samples and the effect of these experiences on the prognosis of their mental illness. As a preventive strategy of IPV, continuous research is recommended to reduce the burden of CMI. IPV was associated with being unemployed or daily labourer/housemaid status in this study which is consistent with the WHO multi-site study, which found employment as a protective factor. ${ }^{6}$ in comparison, findings from other sub-Saharan African countries are not consistent. ${ }^{3435}$ This can be explained by cultural differences and study settings. However, causation cannot be established in our study due to the cross-sectional study design. Further studies are required to develop interventions intended at reducing IPV among women with CMI and test their effectiveness. Even though the participation was voluntary, the fact that no woman declined to participate in this study adds to the strengths of our findings.

\section{CONCLUSIONS}

IPV was found to be highly prevalent among women with CMI living in urban settings in Ethiopia. Given the detrimental effect of IPV on mental health, it may contribute to disparities in CMI clinical outcomes and quality of life among female patients. In addition, unemployment and a longer duration of CMI are associated with a higher prevalence of IPV.

Psychiatric outpatient clinics are an essential point of contact for women with mental illness who are experiencing IPV. The treatment for mental disorders needs to include effective interventions for women who are also IPV victims. Mental health professionals play a key role in addressing IPV in this population.

\section{Twitter Tigist Zerihun @zerihun_tigist}

Acknowledgements We wish to thank all study participants and their caregivers who accompanied them to the hospitals, supervisors and data collectors for their time and commitment to the study.

Contributors TZ, MT, ND and DB conceptualise conceived the study, developed the design. TZ and ND collected and managed data. TZ, ND and DB performed the preliminary data analysis. TZ and MT performed the final data analysis. All authors contributed to the interpretation of results. TZ drafted the manuscript, and all authors contributed to critical revisions of the manuscript. All authors read and approved the final manuscript. TZ, MT, ND and DB accepts full responsibility for the work and the conduct of the study.

Funding This study was supported by St Paul's Hospital Millennium Medical College. Grant number 001/2016. The funder had no role in study design, data collection and analysis, decision to publish, or manuscript preparation.

Competing interests None declared.

Patient and public involvement Patients and/or the public were not involved in the design, or conduct, or reporting, or dissemination plans of this research.

Patient consent for publication Not applicable. 
Ethics approval This project has been approved by the Millennium Medical College Institutional Ethics Review Board at St. Paul's Hospital (Ref. 001/2016). Written informed consent was obtained from participant is informed in detail about the study objectives and possible risks, and the benefits of the study before being enrolled.

\section{Provenance and peer review Not commissioned; externally peer reviewed.}

Data availability statement Data are available upon reasonable request. The authors confirm that the availability of data. Dataset is not publicly available at this point because it contains sensitive information. The data that support the findings of this study are available from the corresponding author, $T Z$, upon reasonable request.

Open access This is an open access article distributed in accordance with the Creative Commons Attribution Non Commercial (CC BY-NC 4.0) license, which permits others to distribute, remix, adapt, build upon this work non-commercially, and license their derivative works on different terms, provided the original work is properly cited, appropriate credit is given, any changes made indicated, and the use is non-commercial. See: http://creativecommons.org/licenses/by-nc/4.0/.

\section{ORCID iD}

Tigist Zerihun http://orcid.org/0000-0001-6566-9053

\section{REFERENCES}

1 Miller E, McCaw B. Intimate partner violence. N Engl J Med Overseas Ed 2019;380:850-7.

2 Organization WH. Responding to intimate partner violence and sexual violence against women: WHO clinical and policy guidelines. Geneva: World Health Organization, 2013.

3 Feder G, Ramsay J, Dunne D, et al. How far does screening women for domestic (partner) violence in different health-care settings meet the UK national screening Committee criteria for a screening programme? systematic reviews of nine UK national screening Committee criteria. Health Technol Assess 2009;13.

4 García-Moreno C, Pallitto C, Devries K, et al. Global and regional estimates of violence against women: prevalence and health effects of intimate partner violence and non-partner sexual violence. Geneva: World Health Organization, 2013.

5 Organization WH. Global and regional estimates of violence against women: prevalence and health effects of intimate partner violence and non-partner sexual violence. Geneva: World Health Organization, 2013.

6 Garcia-Moreno C, Jansen HAFM, Ellsberg M, et al. Prevalence of intimate partner violence: findings from the WHO multi-country study on women's health and domestic violence. The Lancet 2006:368:1260-9.

7 Chernet AG, Cherie KT. Prevalence of intimate partner violence against women and associated factors in Ethiopia. BMC Womens Health 2020;20:22

8 Dixon L, Graham-Kevan N. Understanding the nature and etiology of intimate partner violence and implications for practice and policy. Clin Psychol Rev 2011;31:1145-55.

9 Du Mont J, Forte T. Intimate partner violence among women with mental health-related activity limitations: a Canadian population based study. BMC Public Health 2014;14:51.

10 Patra P, Prakash J, Patra B, et al. Intimate partner violence: wounds are deeper. Indian J Psychiatry 2018;60:494.

11 Dillon G, Hussain R, Loxton D, et al. Mental and physical health and intimate partner violence against women: a review of the literature. Int J Family Med 2013;2013:1-15.

12 Vos T, Astbury J, Piers LS, et al. Measuring the impact of intimate partner violence on the health of women in Victoria, Australia. Bull World Health Organ 2006;84:739-44.

13 Bosch J, Weaver TL, Arnold LD, et al. The impact of intimate partner violence on women's physical health: findings from the Missouri behavioral risk factor surveillance system. $J$ Interpers Violence 2017;32:3402-19.
14 Bonomi AE, Thompson RS, Anderson M, et al. Intimate partner violence and women's physical, mental, and social functioning. $A m \mathrm{~J}$ Prev Med 2006;30:458-66.

15 Devries KM, Mak JY, Bacchus LJ, et al. Intimate partner violence and incident depressive symptoms and suicide attempts: a systematic review of longitudinal studies. PLoS Med 2013;10:e1001439.

16 Coker AL, Davis KE, Arias I, et al. Physical and mental health effects of intimate partner violence for men and women. Am J Prev Med 2002;23:260-8.

17 Afifi TO, MacMillan H, Cox BJ, et al. Mental health correlates of intimate partner violence in marital relationships in a nationally representative sample of males and females. $J$ Interpers Violence 2009;24:1398-417

18 Deyessa N, Berhane Y, Alem A, et al. Intimate partner violence and depression among women in rural Ethiopia: a cross-sectional study. Clinical Practice and Epidemiology in Mental Health 2009;5:8.

19 Hegarty K, Gunn J, Chondros P, et al. Association between depression and abuse by partners of women attending general practice: descriptive, cross sectional survey. BMJ 2004;328:621-4.

20 Leung WC, Kung F, Lam J, et al. Domestic violence and postnatal depression in a Chinese community. International Journal of Gynecology \& Obstetrics 2002;79:159-66.

21 Division UNS. country profile | Ethiopia - UNdata, 2016. Available: https://data.un.org/CountryProfile.aspx/_Images/CountryProfile. aspx?crName=Ethiopia

22 Tsigebrhan R, Shibre T, Medhin G, et al. Violence and violent victimization in people with severe mental illness in a rural lowincome country setting: a comparative cross-sectional community study. Schizophr Res 2014;152:275-82.

23 Saidi Kapiga SH, Muhammad AK, Stöckl H, et al. Prevalence of intimate partner violence and abuse and associated factors among women enrolled into a cluster randomised trial in northwestern Tanzania. BMC Public Health 2017;17:1.

24 Tegbar Yigzaw AY, Kebede Y. Domestic violence around Gondar in Northwest Ethiopia. Ethiopian Journal of Health Development 2004;18:133-9.

25 Oram S, Trevillion K, Feder G, et al. Prevalence of experiences of domestic violence among psychiatric patients: systematic review. British Journal of Psychiatry 2013;202:94-9.

26 Khalifeh $\mathrm{H}$, Oram S, Trevillion $\mathrm{K}$, et al. Recent intimate partner violence among people with chronic mental illness: findings from a national cross-sectional survey. British Journal of Psychiatry 2015;207:207-12

27 González Cases J, Polo Usaola C, González Aguado F, et al. Prevalence and characteristics of intimate partner violence against women with severe mental illness: a prevalence study in Spain. Community Ment Health J 2014;50:841-7.

28 Ali AA, Yassin K, Omer R. Domestic violence against women in eastern Sudan. BMC Public Health 2014:14:1136.

29 Ali TS, Asad N, Mogren I, et al. Intimate partner violence in urban Pakistan: prevalence, frequency, and risk factors. Int J Womens Health 2011;3:105.

30 McCleary-Sills J, Namy S, Nyoni J, et al. Stigma, shame and women's limited agency in help-seeking for intimate partner violence. Glob Public Health 2016;11:224-35.

31 Metheny N, Stephenson R. Help seeking behavior among women who report intimate partner violence in Afghanistan: an analysis of the 2015 Afghanistan demographic and health survey. J Fam Violence 2019;34:69-79.

32 Stöckl H, Penhale B. Intimate partner violence and its association with physical and mental health symptoms among older women in Germany. J Interpers Violence 2015;30:3089-111.

33 Trevillion K, Oram S, Feder G, et al. Experiences of domestic violence and mental disorders: a systematic review and meta-analysis. PLoS One 2012;7:e51740.

34 Cools S, Kotsadam A. Resources and intimate partner violence in sub-Saharan Africa. World Dev 2017:95:211-30.

35 Khan S, Klasen S. Female employment and spousal abuse: a parallel cross-country analysis of developing countries. Discussion Papers 2018. 